\title{
Bark beetle mycobiome: collaboratively defined research priorities on a widespread insect-fungus symbiosis
}

\author{
Jiri Hulcr ${ }^{1}$ (D) - Irene Barnes ${ }^{2} \cdot$ Z. Wilhelm De Beer ${ }^{2} \cdot$ Tuan A. Duong $^{2} \cdot$ Romina Gazis $^{3} \cdot$ Andrew J. Johnson $^{1} \cdot$ \\ Michelle A. Jusino ${ }^{1,4}$. Matthew T. Kasson ${ }^{5}$. You $\mathrm{Li}^{1} \cdot$ Shannon Lynch $^{6} \cdot$ Chase Mayers $^{7}$. Tendai Musvuugwa ${ }^{8}$. \\ Francois Roets ${ }^{9} \cdot$ Katja C. Seltmann ${ }^{10} \cdot$ Diana Six $^{11} \cdot$ Dan Vanderpool ${ }^{12} \cdot$ Caterina Villari $^{13}$
}

Received: 6 April 2020 / Accepted: 18 May 2020 / Published online: 3 June 2020

(C) The Author(s) 2020

\begin{abstract}
One of the main threats to forests in the Anthropocene are novel or altered interactions among trees, insects and fungi. To critically assess the contemporary research on bark beetles, their associated fungi, and their relationships with trees, the international Bark Beetle Mycobiome research coordination network has been formed. The network comprises 22 researchers from 17 institutions. This forward-looking review summarizes the group's assessment of the current status of the bark beetle mycobiome research field and priorities for its advancement. Priorities include data mobility and standards, the adoption of new technologies for the study of these symbioses, reconciliation of conflicting paradigms, and practices for robust inference of symbiosis and tree epidemiology. The Net work proposes contemporary communication strategies to interact with the global community of researchers studying symbioses and natural resource managers. We conclude with a call to the broader scientific community to participate in the network and contribute their perspectives.
\end{abstract}

Keywords Scolytinae $\cdot$ Ambrosia $\cdot$ Invasive species $\cdot$ Mutualism

\section{Introduction}

\subsection{The bark beetle-fungus symbiosis}

Symbiosis is one of the most charismatic phenomena of life. Bark beetles (Coleoptera: Curculionidae: Scolytinae) evolved so many different types of symbioses that they offer an

Jiri Hulcr

hulcr@ufl.edu

1 School of Forest Resources and Conservation, University of Florida, Gainesville, FL, USA

2 Department of Biochemistry, Genetics and Microbiology, Forestry and Agricultural Biotechnology Institute, University of Pretoria, Pretoria, South Africa

3 Tropical Research and Education Center, University of Florida, Homestead, FL, USA

4 Department of Plant Pathology, University of Florida, Gainesville, FL, USA

5 Division of Plant and Soil Sciences, West Virginia University, Morgantown, WV, USA

6 Environmental Studies, University of California-Santa Cruz, Santa Cruz, CA, USA unmatched research system for evolutionary biologists, ecologists, and scientists in plant protection. Most bark beetles are associated with fungi, but the degree and mode of association vary tremendously, possibly more than in any other comparable insect group (Figs. 1 and 2)(Harrington 2005; Mueller et al. 2005). The relationships range from highly specific, farming-like nutritional ambrosia symbioses, to loose

7 Plant Pathology and Plant-Microbe Biology Section, Cornell University, Ithaca, NY, USA

8 Department of Biological and Agricultural Sciences, Sol Plaatje University, Kimberley, Northern Cape, South Africa

9 Department of Conservation Ecology \& Entomology, Stellenbosch University, Stellenbosch, South Africa

10 Cheadle Center for Biodiversity and Ecological Restoration, University of California Santa Barbara, Santa Barbara, CA, USA

11 W.A. Franke College of Forestry \& Conservation, University of Montana, Missoula, MT, USA

12 Department of Biology, Indiana University, Bloomington, IN, USA

13 Warnell School of Forestry and Natural Resources, University of Georgia, Athens, GA, USA 
associations of beetles with fungal hitchhikers, to asymmetrical dependence of beetles on trees pre-colonized by pathogens (Hulcr and Stelinski 2017). Similarly variable are the relationships between the beetle-fungus consortia and their tree hosts. While some bark beetles require killing trees for reproduction (Thatcher 1981), others live in decayed trunks feeding on white-rot fungi ( $\mathrm{Li}$ et al. 2015), and yet others colonize dry twigs accompanied by xerophylic fungi (Kolarík et al. 2008).

The bark beetle mycobiome has the potential to become a research system on the cutting edge of symbiosis research, given its diversity, common availability, and replication of evolutionary origins. However, the field faces challenges similar to those in research on other symbioses: the "dark biodiversity" where researchers have mostly neglected fungi and beetles that are difficult to sample, the difficulties in separating out anecdotal/storytelling from robust evidence-based research, and diffuse community evolution where fitness is hard to measure (Six 2020). Forest entomology and pathology textbooks and papers continue to promulgate concepts that remain unproven by experiments.

Besides serving as a model in ecology and evolutionary biology, these beetle-fungus relationships have often been hugely destructive to forests. Beetle outbreaks and pathogen epidemics have now reached record proportions on nearly every continent. Bark beetles (and the fungal pathogens that some carry) are blamed for this destruction, but in reality, it is far from clear when these are true "pests" and "diseases" and when they are just symptoms of much greater anthropogenic causes, including climate change, globalization, and intensive silviculture (Allen et al. 2010). Forest entomology and pathology literature has been dominated by studies from North American and European ecosystems and plantations, but most of the emerging beetle-associated tree die-offs do not fit established paradigms. This results in lack of solid information on such important agents of disturbance for the end-users of our science (Figs. 1 and 2).

\subsection{The network}

To critically assess the current research on bark beetles, their associated fungi, and their relationships with trees, the Bark Beetle Mycobiome research coordination network was formed (http://www.bbmycobiome.org). This international group of over 22 researchers from 17 institutions, mostly in South Africa and the United States, strives to unite the fields of forest entomology, pathology, symbiology, and tree health, and to strengthen them with new paradigms and technologies appropriate for the era of rapid global change. This forwardlooking review presents the group's assessment of the current status of the field and recommend priorities for advancement.

In order to accelerate discovery, remain compatible with other cutting-edge research fields, and serve applied end users,

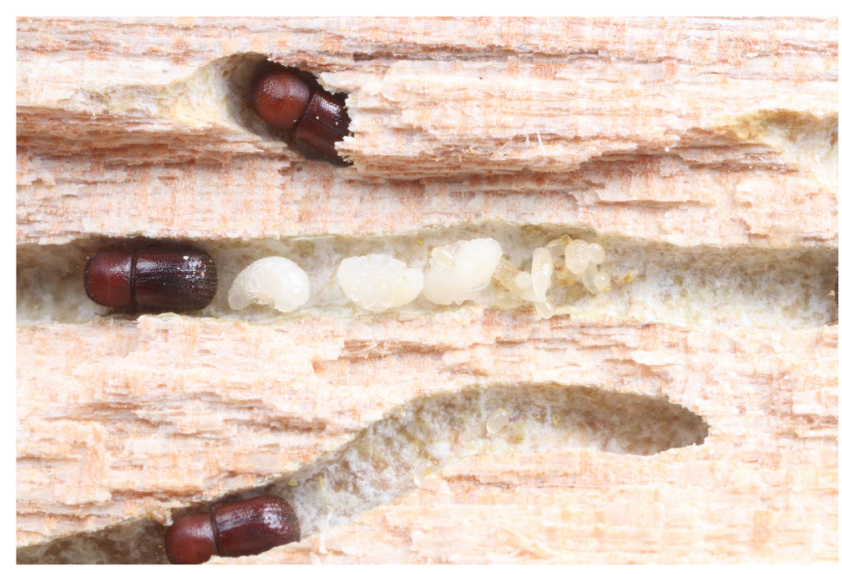

Fig. 1 Ambrosia beetles, such as this Ambrosiodmus minor, are an example of an obligate mutualism between bark beetles and fungi. A. minor depends on its basiodiomycete symbiont Flavodon subulatus (Jusino et al. 2020) for the extraction of nutrients from the dead wood. The fungus, visible here as white mycelium in the tunnels, benefits by being vectored to suitable microhabitats. Photo: You Li, University of Florida

the Network intends to support key conceptual advances in the bark beetle mycobiome research, including:

- Define standards for robust bark beetle-fungus research, including standards for sampling, isolation, storage of material, and data formats.

- Facilitate data sharing through the mobilization of dark data and alignment of our databases with other global data-sharing initiatives.

- Improve research rigor by moving beyond observations towards hypothesis-driven experimental design, symbiosis inference, pathology inference, statistics, and molecular tools.

- Connect the forest pathology and entomology communities working on the topic to one another and to other communities engaged in basic sciences, management, and policy.

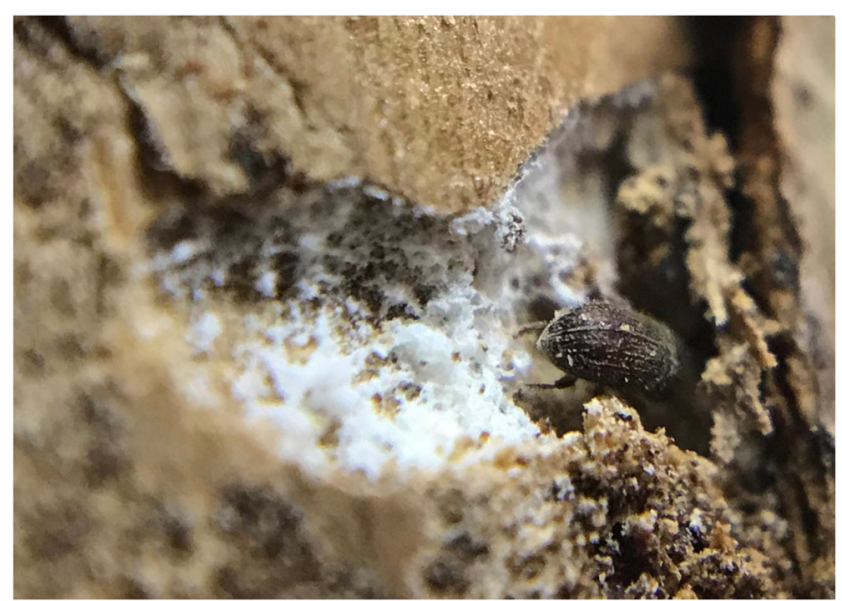

Fig. 2 Most bark beetles live in fungus-saturated spaces, but the cooccurrence does not imply interaction. Here, an unknown fungus flourishes in the tunnel of Hypoborus ficus without any known effect on the phloem-feeding beetle. Photo: Jiri Hulcr 
- Synthesize and publish the new knowledge and perspectives on bark beetle-fungus symbiosis to distinguish what is solidly known or testable, and communicate it.

- Communicate to the global research and end-user community. Communication and access facilitation should be a foundational effort in each research project. The Network attempts to set a standard of openness by making its activities and outputs publicly accessible. The schedule of all activities and the recordings of all quarterly meetings are freely available on our website www.bbmycobiome. org.

The remainder of this review analyses specific elements of the research process.

\section{Design of observations and experiments}

\subsection{Current status}

The development of any research field rests on the interplay between experimental and observational approaches. Also in bark beetle-fungus symbiosis research, hypotheses need to be tested by experimentation, while the most productive way to generate the hypotheses is by learning from natural history. However, statements of function or relationships made from observations are a weak inference, and this approach is identified by the Network as the main roadblock in current research. Observations and experiments are equally important, but both need to be conducted with rigor.

Observations on the biology of bark beetles, ambrosia beetles, and the associated fungi are plentiful in literature. Unfortunately, many published studies employ sampling driven by opportunity, convention, or expected results rather than a systematic and properly documented sampling. As a result, much of the literature is difficult to use as credible foundation for subsequent hypotheses.

The experimental dimension of the research field is lagging even further behind. For example, one of the most fundamental and often explored concepts is the relationship between a particular fungus isolated from a particular beetle gallery and the biology of the beetle. Dozens of projects describing new beetle-fungus associations have deployed weak sampling schemes and were only able to report correlative associations between the organisms. This weak post-hoc observational inference is equally widespread in studies of beetle-borne diseases of trees. Several recent works confirm that the system does yield itself to experimentation and strong inference (Six and Elser 2019; Carrillo et al. 2020).

One of the greatest benefits of studying the bark and ambrosia beetle mycobiome is its multiple independent evolutionary origins, because it allows the application of powerful comparative studies. Unfortunately, this opportunity remains underused, as only very few bona fide comparative studies exist (Huang et al. 2019, 2020; Veselská et al. 2019).

\subsection{Recommended priorities for advancement}

As in all of symbiology, the research field will advance best if natural history observations are systematically recorded and corroborated via hypothesis-driven experimentation. Other fields, from climate research to epidemiology, have adopted standards for data reporting to bolster the value of observations (Boden and Parkin 2008, Halbritter et al. 2019) and we advocate for analogous standards to be used in our field.

Even initial observations in an unknown system can be recorded with rigor. Instead of recording "a white fluffy fungus growing in the tunnels of beetle X", one can follow standards for a descriptive study and record "between the hatching and pupation stage of the brood a translucent mycelium with monilioid conidiophores, consistent with the appearance of Ambrosiella, grew along the walls of the larval cradles" and include the tree host, location, a photograph, and a voucher. The additional effort required for making and recording detailed observations is small, but the value for subsequent research is substantially greater.

Similarly, in terms of hypothesis testing design, we believe that the lack of rigor is less a matter of logistics and effort and more a lack of culture of experimental design in the field. How can we assert that a fungus isolated from a beetle is a mutualist, commensal, parasite, or just one of the myriads of fungi naturally occurring in the subcortical habitat? This cannot be inferred from its presence or even repeated presence and great abundance. The path to the most reliable statements of role and relationship (mutualism, parasitism) is via replicated, factorial experiments on the effect of the presence and absence of the fungus (e.g. Bracewell and Six 2015, French and Roeper 1972, Saucedo et al. 2018, Carrillo et al. 2020).

One potential avenue for change in the community culture is the encouragement of robust peer-review practices. For example, the publication of works without a satisfactory factorial design or evolutionary studies without a comparative framework should be discouraged.

\section{Mycobiome sampling}

\subsection{Current status}

As studies of the bark beetle mycobiome are expanding from the discovery phase into understanding of function and interactions, rigorous sampling standards are essential. Unfortunately, the community of researchers studying the bark beetle mycobiome does not share standard best practices for acquiring specimens, sampling, isolating and curating fungi, and implementing experiments. Often, the choice of the 
sampling method is driven by convenience or by convention, not by the targeted question. Consequently, the literature on bark beetles and fungi is replete with tenuous claims of associations without exploring alternative hypotheses. Frequently there are no fungus or beetle vouchers. Sources of contamination and bias are introduced in the downstream community analyses, rather than removed.

Sampling of the bark beetle mycobiome tends to be biased towards particular species or groups of fungi, especially those causing disease. Cryptic species (Lehenberger et al. 2019), bacteria (Hulcr et al. 2012), yeasts (Mayers et al. 2018), phoretic and fungus-feeding mites and nematodes, and contaminating molds (e.g., Penicillium, Aspergillus, Mucoromycetes) have been overlooked, ignored, or disposed of (Davis 2015; Kasson et al. 2016; Li et al. 2018; Hofstetter et al. 2015), despite their ubiquity and abundance in beetle galleries and mycangia.

\subsection{Recommended priorities for advancement}

To improve our understanding of species interactions associated with the bark beetle mycobiome and to distinguish biologically relevant partners from transient organisms, sampling practices must address these gaps:

- Normalized sampling approaches to ensure data quality and parity across the scope of research on bark beetlefungus interactions.

- Strategies for isolating fungi must be tailored to specific questions (e.g., identification vs. microbiome studies), and isolation methods to different substrates.

- Currently used storage techniques for fungi need to be reviewed (e.g., slants, lyophilization, storage multiplexing) and examined for their influence on beetle-associated fungal mortality and recovery bias.

- Often the best approach to isolate the fungal community is sampling directly from the beetle vectors, but best practices for sampling, storing, and shipping beetles for fungal isolation have not been established.

- High-quality voucher specimens for unequivocal future references need to be included in the workflow.

- To facilitate collaborative research, collections with beetle-associated fungi, specimens, and cultures need to be identified and connected.

\section{Vector beetle identification}

\subsection{Current status}

Bark and ambrosia beetles are often perceived as difficult to identify. Many publications only identify them to genus, and the method of identification is often not described. Vouchers are not always kept or made accessible, either physical specimens or DNA barcode sequences. Interestingly, this issue is pervasive in studies of species that are perceived as common.

The greatest taxonomic scrutiny is typically dedicated to emerging pest species. This is appropriate but it results in frequent taxonomic renaming, which makes it difficult for the end-users to adopt the correct nomenclature. For example, Euwallacea fornicatus (Eichhoff 1868) sensu Wood (2007) is different from Euwallacea fornicatus (Eichhoff, 1868) sensu Gomez et al. (2018) and Euwallacea fornicatus (Eichhoff 1868) sensu Smith et al. (2019b).

Another reason why corroboration of species identity is more important than ever is the exponential growth of available DNA sequences (Cognato et al. 2020). Publications not following the newest classification risk the perpetuation of incorrect data, and make navigating past results difficult.

\subsection{Recommended priorities for advancement}

The Network identified four areas where practical improvements are within reach:

- Facilitating the rigor of beetle identification: When an observation or inference is made of bark and ambrosia beetles interacting with fungi, the identity of the beetle should be rooted in literature or corroborated with a person who made the identification. In the last few years, user-friendly identification tools have been made available (i.e., www.barkbeetles.info) or are being published (e.g., Smith et al. 2019a), including curated DNA sequence databases (Cognato et al. 2020). Furthermore, recognizing the need for increased identification rigor, the research community has organized itself to provide free bark and ambrosia identification service (i.e., www.ambrosiasymbiosis. org/mysterybeetles). Our Network will work to popularize the use of such tools and services and will continue to support them.

- Synergy between ongoing taxonomic research and its use by the broader community: the research community need to understand the end-user community and facilitate its access to the most robust, up-to-date nomenclature. This is important not only for reproducible science but also for fair attribution of impact to taxonomic publications (Agnarsson and Kuntner 2007). At the same time, publicizing emerging species of importance assists the taxonomy-oriented members of our community with prioritizing their research focus.

- New approaches for identification: artificial intelligence is being explored in beetle morphological identification (i.e. http://beetle.ioz.ac.cn). DNA-based identification 
works best when using expert-curated resources (Cognato et al. 2020).

- Training: Recognizing that in-person training in beetle identification is most productive, the group co-supports hands-on taxonomic training opportunities, such as the Bark \& Ambrosia Beetle Academy.

\section{Fungus identification}

\subsection{Current status}

Morphology-based identification of bark beetle-associated fungi is difficult: most have few diagnostic characters, some of their most conspicuous traits are convergent, and most nutritional mutualists lack sex-related morphology, and identification based only on asexual spore-producing structures can be misleading (Batra 1985). For example, beetle-associated fungi in the unrelated orders Ophiostomatales and Microscales independently evolved nearly identical long-necked perithecia that attach sticky ascospore masses onto insect cuticles (Blackwell 2010; De Beer et al. 2013).

Molecular identification of fungi has become the standard in the field, but the widespread reliance on DNA barcoding (the use of single short gene regions for species identification) or metabarcoding (the use of the same regions for surveys of communities) has several drawbacks (see below for a discussion on DNA and RNA metabarcoding). The two most frequent issues that our group identified are the use of inappropriate PCR primers and the low reliability of DNA sequence databases. Sequence comparison is only useful if databases are properly populated. Unfortunately, DNA sequences of beetleassociated fungi in public databases are still often incorrectly named (Nilsson et al. 2006). Reliable identification is dependent on phylogenetic analyses using reference data sets, which is challenging for non-systematists.

\subsection{Recommended priorities for advancement}

The identity of a beetle-related fungus is not just a name label; it should be used as a statement about the evolutionary origin of the fungus, its relationship to the beetle vector, and its role in the holobiome. Existing DNA sequence datasets need to be curated to become identification resources where species identities are corroborated by the congruence of DNA-phylogenetic, morphology, and ecological distinctiveness. Most of the information already exists but our goal is to make it interconnected, revised and widely available.

\section{DNA and RNA metabarcoding}

\subsection{Current status}

Contemporary amplicon metabarcoding of fungal communities largely relies on the internal transcribed spacer region (ITS) of the ribosomal RNA (rRNA) array. However, for many subcortical fungi including key beetle symbionts from Ophiostomatales, this marker is unreliable for amplification (Harrington et al. 2011). The impact of this bias is underappreciated (Skelton et al. 2019b), and undermines the conclusions of many studies, including our earlier studies (Kostovcik et al. 2015; Rassati et al. 2019; Miller et al. 2019). Additional biases are present at most steps of this process, including the treatment of the beetle vector, sampling design, DNA extraction, amplification, sequencing, read clustering, and incomplete public DNA databases (Lindahl et al. 2013).

Many metbarcoding studies still use the sequencing technology for untargeted surveys, generating large amount of data first and speculating about emergent patterns later. These exercises miss the greatest power of high-throughput sequencing: the statistical testing of pre-defined hypotheses by multiplexing, disaggregation of samples, factorial design, and replication. Communities in mycangia have been characterized repeatedly using DNA metabarcoding but hypotheses about interactions of the fungi are only now beginning to be addressed (Skelton et al., 2019b).

The resulting beetle-by-fungi matrix is a starting point for downstream analyses. Because the fungi and beetles may or may not be phylogenetically related, a key challenge in disentangling the community is distinguishing the effect of ecological processes from the shared evolutionary history of some members (Skelton et al. 2019a). This is where the phylogenetic replication bark beetle mycobiome presents an unprecedented playfield for development (Huang et al. 2019; Veselská et al. 2019; Skelton et al. 2019b).

\subsection{Recommended priorities for advancement}

Standards in DNA metabarcoding studies of the beetleassociated fungal communities need to be elevated. On the conceptual level, we recommend an integrated design of such studies, where the sampling design, the choice of markers and the bioinformatic steps are steered by biological properties of the system and, first and foremost, by the research question.

On the technical level, biases at many steps of the highthroughput sequencing process can be circumvented by including additional markers, complementary culturing (Skelton et al. 2019b) and appropriate controls. We strongly suggest that the use of controls - negative blanks, expected taxa, mock communities, and synthetic DNA - becomes the standard in mycobiome research (Palmer et al. 2018). Controls allow researchers to determine which organisms are 
true members of the bark beetle mycobiome, which are contaminants and how they were introduced (Lindahl et al. 2013).

For robust future DNA metabarcoding of fungal communities associated with bark and ambrosia beetles, approaches beyond single-marker metabarcoding should be explored. Other fields are successfully testing secondary barcodes such as LSU, TEF and beta tubulin, and long barcode sequences using technologies such as Pacific Biosciences (PacBio) and Oxford Nanopore (Nilsson et al. 2019).

\section{New molecular approaches}

\subsection{Current status}

The frontier of the research on beetle-fungus relationship is in interactions on the cellular level. Tools needed for such research, including transcriptomics, experimental genome modification or fluorescence in-situ hybridization, are readily available and have revolutionized other fields of biology, but they have never been used to study the bark beetle mycobiome.

\subsection{Recommended priorities for advancement}

The research field needs to start studying the mechanisms of the interactions between the insects and fungi. This is possible with the recent advancements in omics technologies, including whole metagenome shotgun sequencing, metatranscriptomics, and metaproteomics. These technologies offer exciting research opportunities at scales from molecular signaling between symbiont tissues to metacommunities and metasymbioses (communities of symbioses). The bark beetle mycobiome system promises to fully utilize the power of these methods as it offers comparative studies with phylogenetically independent replicates and factorial hypothesis-testing.

While the symbiosis function remains a true black box, even the fungus community composition is still not fully understood. Amplicon metabarcoding has provided new insights into the low-titer community members, however, it also introduced new biases. Studies in other fields have demonstrated the utility of amplicon-free approaches capable of detecting very small amounts of environmental DNA (eDNA). A pilot target-capture approach (Vanderpool, unpublished) designed to identify bark beetle consortia has the power to identify all known and many unknown associates including the beetle, bacteria, viruses, nematodes, mites, prokaryotes such as Wolbachia, fungi, and microsporidia in a single library. We are currently optimizing this protocol for use as a resource to the bark beetle mycobiome research community.

\section{Data culture and data sharing}

\subsection{Current status}

Most specimens that support the active research on bark beetles and their mycobiome are kept in disparate laboratories that are not shared or made public. The number of specimens (fungal or beetle) from the bark beetle-fungus research community that are shared in iDigBio (https://www.idigbio.org), SCAN (http://scan-bugs.org), MyCoPortal (http://mycoportal. org), or GBIF is low (Fig. 3). In addition, most of these data are from specimens preserved in museums, not in active labs, and are extremely geographically uneven. This is a drawback for the community because the contents are unknown, and it also puts the burden of data curation, sharing and archiving on each lab, rather than a larger, specialized data serving community. Individual database solutions typically do not follow biodiversity data sharing standards (e.g., Darwin Core, EML) so sharing data becomes difficult, or impossible, even if the desire exists.

\subsection{Recommended priorities for advancement}

Capture of standardized data is now routine practice in many other research fields and public sharing is an important step (Parr and Cummings 2005). Some data types are already produced by nearly every team of bark beetle mycobiome researchers, including sample provenance, images and DNA sequences, and the majority are readily publishable through existing online resources (e.g., journal supplementary materials, GBIF, iDigBio, NCBI). The uniquely valuable data on the associations between the beetle, fungus and tree species are publishable through synthetic dataset initiatives such as the Global Biotic Interactions, open-access data repositories such as Zenodo (https://zenodo.org/); and language standardization projects like the Relations Ontology (http:// www.obofoundry.org/ontology/ro.html). Access to raw data from research is important to advance our science, providing sufficient detail to allow the methods to be replicated and the results compared (Cassey and Blackburn 2006, Heidorn 2008, Ellison 2010).

The Network recommends developing the culture of data sharing by: 1) finding and promoting existing mechanisms that make data sharing beneficial to both the community as well as to the original investigators, 2) establishing workflows that elucidate "dark data" (unknown or unsearchable data) in the labs of the bark beetle mycobiome research community, 3) promoting minimum standards for these data that align with the larger biology data standards for sharing and reuse, and 4) examining how other research communities solved data sharing (e.g., DataOne, KNB Data Repository, Michener et al. 2011). 


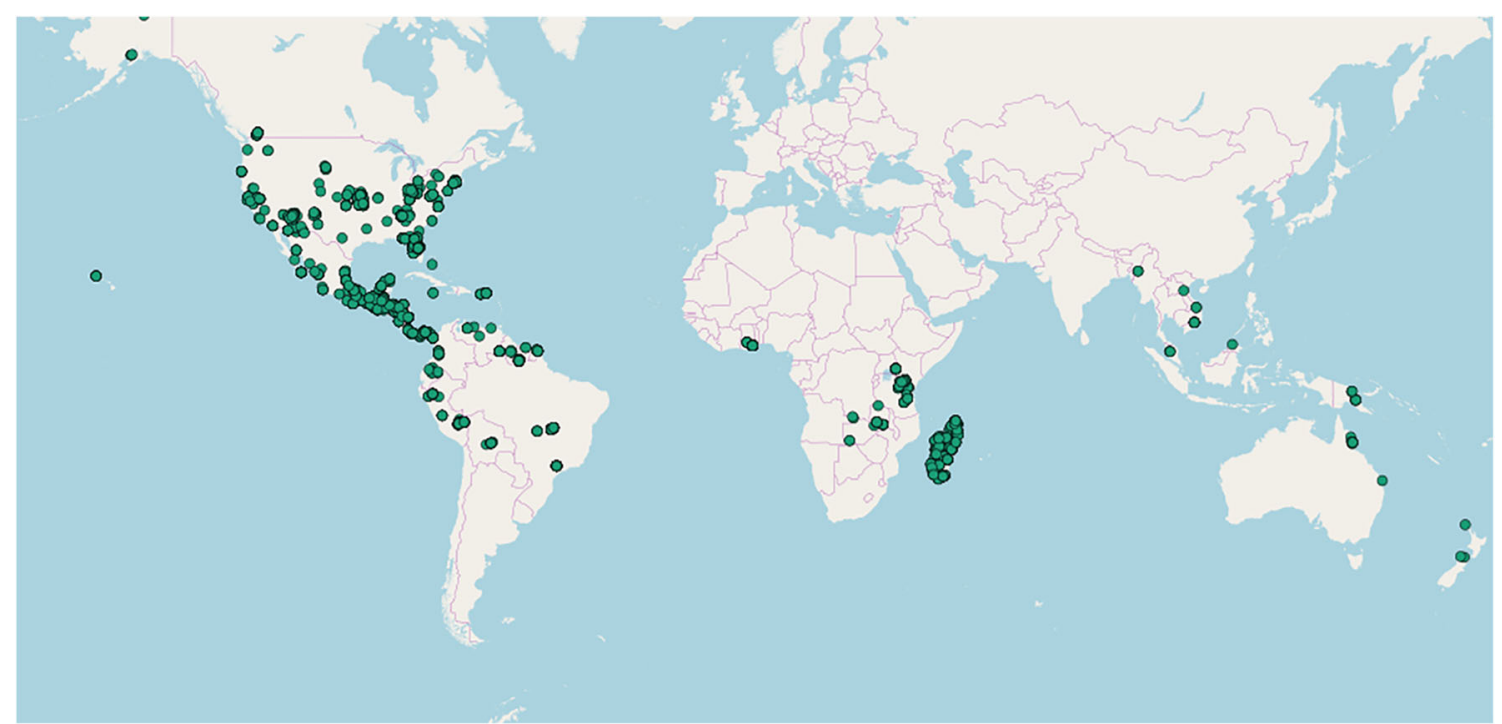

Fig. 3 Map of the 12,778 records of Scolytinae records in iDigBio out of the 115,621,381 available records (iDigBio 2018) shows highly uneven global representation

\section{The importance of the host plants}

\subsection{Current status}

Almost the entire lifespan of every bark beetle mycobiome member takes place inside a host tree. This environment is far from inert, as plants respond to the presence of external agents (Bonello et al. 2006), and the microenvironment undergoes major changes after the tree's death. In some cases, the need to overcome host responses might even be one of the main selection forces for a beetle-fungal consortium (Hammerbacher et al. 2019). Hence, the host plant is a critical component of the ecology of the beetle-fungus symbioses (e.g., Wallace 1859; Raffa 2014), whether this involves asymptomatic interactions, the development of a disease and death of the host, or colonization of dead wood.

Except for the beetle-fungal systems that are well-studied pests, the ecological role of the host tree is often underemphasized. In most studies on non-pest systems, the host trees are not even fully identified, and their interaction with the invading agents is often ignored. Collection and preservation of plant tissue as vouchers is rare, as is their molecular confirmation.

\subsection{Recommended priorities for advancement}

It is prudent that the role of tree identity and tree stress in bark beetle outbreaks and invasions is studied, or at least recorded more rigorously. For many research questions, it may be desirable to also include host physiology and secondary metabolism component. Best practices to sample and preserve host material need to be established and adopted, in order to facilitate future host identification, characterize its physiology, and to control for the intraspecific variability of secondary metabolites (Moore et al. 2014). Input is needed from botanists and plant physiologists.

\section{Defining pests and pathogens}

\subsection{Current status}

Different beetle-fungal consortia cause different types of disease on different plant hosts. While Dutch elm disease, Fusarium dieback, and laurel wilt may have similar effects in the invaded landscapes (Karnosky 1979; Kendra et al. 2013; Boland 2016), the biology of the vectors and the pathogens differs substantially.

The field of plant pathology provides powerful research designs for resolving the contributions of vectors, pathogens and the host to the disease, including Koch's postulates and Leach's rules (Bosso et al. 2012). In the bark beetle/fungus research field, however, the prevailing approach is still to infer causation from observations (Roberts 1977; Hijii et al. 1991; Kovach and Gorsuch 1985; Kühnholz et al. 2001; Bumrungsri et al. 2008; Tarno et al. 2016; Faccoli et al. 2016).

Another useful paradigm in tree health research is the disease triangle - the interplay between the pest/pathogen, the host, and the host's environment. Reporting the host physiological indicators is a standard practice in plant pathology, but it would be an innovation in bark beetle studies. In our system, the interactions are better represented as a pyramid of interactions between the vector beetle, the fungus, the host tree identity, and the environment (Agrios 2005). 


\subsection{Recommended priorities for advancement}

To stem the ongoing proliferation of tenuous observational inferences, we propose to normalize the use of strong inference methods such as Koch's postulates and Leache's rules. We also recommend not to use arbitrary methods to inoculate living plant hosts at different developmental stages and conditions, but methods justified by each project's goal. Knowing when and what to measure is becoming particularly important as molecular, culture-independent techniques for pathogen detection are now commonplace but their interpretation is by no means straightforward (Hulcr et al. 2012).

\section{Innovating research on pest and pathogen systems}

\subsection{Current status}

As global homogenization continues to affect the interactions between bark beetles, fungi, and trees, it is important to continue to adapt the research foci, hypotheses, and tools to in order to understand these new dynamics. Major long-standing questions are still unanswered, while new challenges are emerging. The invasion pathways remain unclear (Turbelin et al. 2017). The importance of tree physiology in pest and disease outbreaks continues to be speculated but rarely tested (Kolb et al. 2019).

\subsection{Recommended priorities for advancement}

To consolidate the current conflicting perspectives on pests and pathogens, and to provide a strong foundation for future development, we encourage researchers on important bark beetle-fungus systems to adopt strong inference standards (Platt 1964). Such standards should become expected in publications and in the peer-review process.

In addition, the field will move forward in greater leaps if more high-risk/high-reward ideas are tested. Below are several examples of classical or novel ideas that promise progress:

- Some ambrosia beetles appear to concentrate on previously injured or stressed trees or tree parts: do they follow cues from the internal tree mycobiome? Can we manage the attacks by modulating the tree mycobiome?

- Bark and ambrosia beetles are temporally synchronized: responding to their phenology may improve pest management in horticulture.

- Pathogenicity or virulence of some invasive beetle-fungus partnerships seem to change with time: can we facilitate the evolution of lower virulence?

- Why are some unrelated tree species more susceptible to beetle or fungus attack than others? Answers may lie in their chemical, volatile, or endophyte similarity rather than their identity.

- Similarly, within-species host tree responses to beetles or fungi are far from uniform. Harnessing host variability in silviculture may be more productive than combating pest and disease outbreaks in uniform stands.

- Protecting trees by stimulating their inducible defense system remains largely untested but some trials are promising (Postma and Goossen-van de Geijn 2016; Mageroy et al. 2019).

Besides new, thought-provoking approaches, the research field also needs to embrace time-tested approaches. For research on insect and fungus distribution, dynamics or etiology, we encourage strategically planned sampling design (e.g., Kolb et al. 2019). It is important to replicate the factors in question, rather than sample ad hoc, based on convenience, or introduce bias by sampling only positive cases.

\section{Terminology in the bark beetle - fungus system}

\subsection{Current status}

During the more than 100-year history of research in this system, the terminology used to describe the organisms, their biological roles, and their relationships has not been consistent. Terms have become confused across time (between the classic and current literature), space (among different countries and languages), and disciplines (for example, between entomologists and mycologists).

Examples of the many terms that are ubiquitous in the literature but lack an agreed-upon definition include:

- primary ambrosia fungus

- auxiliary fungus

- propagule (spore or mycelium fragment)

- transmission (surface versus mycangial)

- nutrition (primary nutrition versus opportunistic, supplementary feeding)

- aggressive pest

- pit mycangium and other non-glandular mycangia

A uniquely problematic term is "associate", as in, a fungal associate of a beetle. The term is sometimes useful as a statistical concept of co-occurrence. The problem is its common misuse as a statement of belief in the biological relevance of the fungus for the beetle, even if other interpretations are more parsimonious (Vega and Biedermann 2019). "Fungal symbiont" is also commonly misused to mean "fungal mutualist", a problem shared with many other symbiotic systems (Bronstein 2015). 


\subsection{Recommended priorities for advancement}

Though the field thrives on interdisciplinary cooperation, the entomologists, mycologists, tree pathologists, botanists, horticulturalists, ecologists, and others will communicate more effectively when using unambiguous terminology (Six 2003; Bronstein 2015; Biedermann and Vega 2019). Ideally, researchers should define terms within publications, or aligned with relevant ontologies (Madin et al. 2008; Reichman et al. 2011).

The Bark Beetle Mycobiome network members, as well as other colleagues (e.g., Biedermann and Vega 2019), have already set out to 1) examine the literature to identify inconsistent and ambiguous descriptors of the symbiosis, 2) examine contemporary biodiversity informatics, ontologies, trait definitions and semantic statements, and 3) produce a set of terms useful in the bark beetle-fungus context aligned with definitions that are either unambiguous or testable.

\section{Communication strategy}

\subsection{Current status}

The magnitude and quality of research on beetles and their fungal partners has increased appreciably in recent years, and the research community has grown by an order of magnitude. The cutting edge of bark beetle symbiology is now a bustling scientific endeavor testing contemporary paradigms and using modern technologies. However, the advances have not been communicated well to outside researchers, natural resource managers, and policymakers. Spread of conflicting information is common, while at the same time, some researches have guarded research information. As a result, many new colleagues are entering the field reading outdated or disproven literature, and many newly published studies are using inadequate design and are addressing questions long answered.

The second, more practical reason for improving our communication is the accelerating avalanche of invasive beetles and fungi, as well as the mounting environmental pressure which causes trees to succumb to beetles and fungi. These are new realities in applied forest protection, yet forest managers are often left with old information that is not applicable to contemporary problems. For example, during the epidemics of laurel wilt, only minimal information was available, the response was slow and the epidemics easily escaped (Hughes et al. 2017). This disease has the potential to inflict major damage in ecosystems in Western, Central and South America, and up-to-date knowledge on the pathosystem needs to be accessible.

Similarly, the common meme "bark beetles and ambrosia beetles kill trees" is misleading. The vast majority of these beetles and fungi are entirely harmless to living trees. There are several species that kill trees under special circumstances. However, most of those circumstances are a result of unnatural silviculture or introduction of nonnative species. The few cases when bark beetles kill trees naturally, it happens as part of long-term cycle of forest disturbance and regeneration (Pec et al. 2015).

\subsection{Recommended priorities for advancement}

The group considers communication to be one of the central elements of modern science. We see several major opportunities for disseminating innovation: 1) involving the community of our peers, 2) training of students, 3) educating entomologists in mycology and vice versa (as recommended by others, e.g., (Raffa et al. 2020), 4) aggressively keeping communication open and equitable, including using social media (Darr et al. 2020), in order to maintain engagement of external colleagues, and 5) identifying services and assistance that are low-cost to existing experts and high-value for new colleagues (for example, free sample identification, https://www. ambrosiasymbiosis.org/mysterybeetles).

The Network wishes to set an example by making its activities publicly accessible via five annual meetings on three different continents, quarterly public online conferences, and ultimately via a published volume of conclusions and recommendations. The schedule of all activities and the recordings of all the quarterly meetings are available on our website www.bbmycobiome.org.

\section{Conclusion}

\subsection{Fundamental questions for the future}

Research on beetle-fungus symbiosis has made major strides in the last decade. However, it still lacks a solid theoretical background and mechanistic understanding. This is especially pronounced when compared with the advanced state of research on other comparable fungus-insect symbioses such as the fungus-farming ants and termites (Aanen et al. 2009; Mueller et al. 2018). Therefore, one of the immediate research directions opened ahead is simply to test the hypotheses already developed for similar symbiotic systems (Nobre et al. 2010).

Another key finding of the recent decade which opened the door to new research realm is the realization that there is not one, but may symbioses between scolytine beetles and fungi. (Hulcr and Stelinski 2017). Each is composed of pairings of beetles and fungi that evolved independently but to some degree convergently (O'Donnell et al. 2015; Bateman et al. 2016, Li et al. 2015, Johnson et al. 2018, Vanderpool et al. 2018; Mayers et al. 2019). This is unique compared to other 
insect-fungus symbiotic systems that typically evolve only once in insect and/or fungus. Therefore, another new research horizon is finding out how these symbioses differ and how they converge.

Most effort in this research field has gone into identifying the nutritional mutualists or phytopathogens vectored by the beetles. Indeed, significant progress has been made, especially in the past decade, identifying and classifying these microorganisms. However, other members of both gallery and mycangium microbiomes have been overlooked or under-emphasized (Hofstetter et al. 2015; Lehenberger et al. 2019).

Many previously unanswerable questions on the microbial and molecular level can now be answered thanks to the availability of high-throughput DNA-based tools and statistical tools for microbial community analysis. To accelerate our understanding of the beetle-fungus symbioses in productive directions, we now also need to adopt inference frameworks long-established in other fields, such as population dynamics, comparative phylogenetics, and multivariate statistics, and only then choose the technology most suitable for the question.

The aspect of bark beetles and fungi relevant to most people is their effect on trees and forests. On one hand, the economic and ecological impact of the bark beetles and their fungi is one of the great reasons for the popularity of the research field. On the other hand, the concept of impact is becoming a burden in our attempts to document the symbioses as part of nature, not at odds with it. The prevailing approach to the study of the beetles and the fungi is to focus on the impact, inherently implying that their ecology, interactions with trees and outbreaks are somehow unnatural. We believe that, instead of focusing on the beetle's impact, we need to study their role in the evolution of ecosystems. The large outbreaks of the beetles and their synergy with climate change make sense from a long term, large scale ecological perspective (Bentz et al. 2010; Hlásny and Turčáni 2013).

\subsection{Call for participation}

The outputs from the research coordination efforts of the Bark Beetle Mycobiome network is intended to be collaborative, international and interdisciplinary. We encourage any readers in the field to lend their voices to the deliberations online (see possibilities for participation at www.bbmycobiome.org). We also welcome perspectives that are currently missing in our community, because expertise and techniques from different fields may allow for unanticipated leaps in the development of the field.

Acknowledgements The Bark Beetle Mycobiome International Research Coordination Network is funded by the National Science Foundation of the USA and the National Research Foundation of South Africa.
Open Access This article is licensed under a Creative Commons Attribution 4.0 International License, which permits use, sharing, adaptation, distribution and reproduction in any medium or format, as long as you give appropriate credit to the original author(s) and the source, provide a link to the Creative Commons licence, and indicate if changes were made. The images or other third party material in this article are included in the article's Creative Commons licence, unless indicated otherwise in a credit line to the material. If material is not included in the article's Creative Commons licence and your intended use is not permitted by statutory regulation or exceeds the permitted use, you will need to obtain permission directly from the copyright holder. To view a copy of this licence, visit http://creativecommons.org/licenses/by/4.0/.

\section{References}

Aanen DK, Henrik H, Debets AJ, Kerstes NA, Hoekstra RF, Boomsma JJ (2009) High symbiont relatedness stabilizes mutualistic cooperation in fungus-growing termites. Science 326:1103-1106

Agnarsson I, Kuntner M (2007) Taxonomy in a changing world: seeking solutions for a science in crisis. Syst Biol 56:531-539

Agrios GN (2005) Plant pathology, 5th edn. Elsevier-Academic Press, San Diego

Allen CD, Macalady AK, Chenchouni H, Bachelet D, McDowell N, Vennetier M, Kitzberger T, Rigling A, Breshears DD, Hogg EH, Gonzalez P, Fensham R, Zhang Z, Castro J, Demidova N, Lim J-H, Allard G, Running SW, Semerci A, Cobb N (2010) A global overview of drought and heat-induced tree mortality reveals emerging climate change risks for forests. For Ecol Manag 259:660-684

Bateman C, Huang Y-T, Simmons DR, Kasson MT, Stanley EL, Hulcr J (2016) Ambrosia beetle Premnobius cavipennis (Scolytinae: Ipini) carries highly divergent ascomycotan ambrosia fungus, Afroraffaelea ambrosiae gen. nov. sp. nov. (Ophiostomatales). Fungal Ecol 25:41-49

Batra LR (1985) Ambrosia beetles and their associated fungi: research trend and techniques. Proc Indian Acad Sci 94:137-148

Bentz BJ, Régnière J, Fettig CJ, Hansen EM, Hayes JL, Hicke JA, Kelsey RG, Negrón JF, Seybold SJ (2010) Climate change and bark beetles of the Western United States and Canada: direct and indirect effects. Bioscience 60:602-613

Biedermann PHW, Vega FE (2019) Ecology and evolution of insectfungus mutualisms. Annu Rev Entomol 65:22.1-22.25

Blackwell M (2010) Fungal evolution and taxonomy. Biocontrol 55:7-16

Boden LA, Parkin TDH (2008) Current guidelines on good reporting of analytical observational studies in epidemiology. Equine Vet $\mathrm{J}$ 40(1):84-86

Boland JM (2016) The impact of an invasive ambrosia beetle on the riparian habitats of the Tijuana River valley, California. PeerJ 4: e2141

Bonello P, Gordon TR, Herms DA, Wood DL, Erbilgin N (2006) Nature and ecological implications of pathogen-induced systemic resistance in conifers: a novel hypothesis. Physiol Mol Plant Pathol 68:95-104

Bosso L, Varlese MER, Ruocco M, Garonna AP, Bonanomi G, Mazzoleni S, Cristinzio G (2012) Severe outbreak of Fusarium solani on Quercus ilex vectored by Xylosandrus compactus. J Plant Pathol 94:S4.99

Bracewell RR, Six DL 2015. Experimental evidence of bark beetle adaptation to a fungal symbiont. Ecology and evolution, 5(21): 51095119.

Bronstein JL (2015) Mutualism. Oxford University Press, Oxford, England, UK

Bumrungsri S, Beaver R, Phongpaichit S, Sittichaya W (2008) The infestation by an exotic ambrosia beetle, Euplatypus parallelus (F.) (Coleoptera: Curculionidae: Platypodinae) of Angsana trees 
(Pterocarpus indicus Willd.) in southern Thailand. Songklanakarin J Sci Technol 30:579-582

Carrillo D, Dodge C, Stouthamer R, Eskalen A (2020) Fungal symbionts of the polyphagous and Kuroshio shot hole borers (Coleoptera: Scolytinae, Euwallacea spp.) in California can support both ambrosia beetle systems on artificial media. Symbiosis $7: 1-4$

Cassey P, Blackburn TM (2006) Reproducibility and repeatability in ecology. BioScience 56(12):958-959

Cognato AI, Sari G, Smith SM, Beaver RA, Li Y, Hulcr J, Jordal BH, Kajimura H, C-S L, Pham TH, Singh S, Sittichaya W (2020) The essential role of taxonomic expertise in the creation of DNA databases for the identification and delimitation of southeast Asian ambrosia beetles species (Coleoptera: Curculionidae: Scolytinae: Xyleborini). Front Ecol Evol 8:27

Darr M, Hulcr J, Eickwort J, Smith J, Hubbard W, Coyle D (2020) Meet them where they are: Facebook as an effective digital diagnostics tool for the natural resources. J Ext in press

Davis TS (2015) The ecology of yeasts in the bark beetle holobiont: a century of research revisited. Microb Ecol 69:723-732

De Beer ZW, Seifert KA, Wingfield MJ (2013) The ophiostomatoid fungi: their dual position in the Sordariomycetes. Pages 1-9 the ophiostomatoid fungi: expanding frontiers. CBS, Utrecht

Ellison AM (2010) Repeatability and transparency in ecological research. Ecology 91:2536-2539

Faccoli M, Campo G, Perrotta G, Rassati D (2016) Two newly introduced tropical bark and ambrosia beetles (Coleoptera: Curculionidae, Scolytinae) damaging figs (Ficus carica) in southern Italy. Zootaxa 4138:189-194

French JR, Roeper RA 1972. Interactions of the ambrosia beetle, Xylebrus dispar, (Coleaopera: Scolytidae), with its symbiotic fungus Ambrosiella hartigii (Fungi imperfecti). The Canadian Entomologist, 104(10): 1635-1641.

Gomez DF, Skelton J, Steininger MS, Stouthamer R, Rugman-Jones P, Sittichaya W, Rabaglia RJ, Hulcr J (2018) Species delineation within the Euwallacea fornicatus (Coleoptera: Curculionidae) complex revealed by morphometric and phylogenetic analyses. Insect Syst Divers 2:1-11

Halbritter AH, De Boeck HJ, Eycott AE, Reinsch S, Robinson DA, Vicca S, Berauer B, Christiansen CT, Estiarte M, Grünzweig JM, Gya R (2019) The handbook for standardized field and laboratory measurements in terrestrial climate change experiments and observational studies (ClimEx). Methods Ecol Evol 11:22-37

Hammerbacher A, Kandasamy D, Ullah C, Schmidt A, Wright LP, Gershenzon J (2019) Flavanone-3-hydroxylase plays an important role in the biosynthesis of spruce phenolic defenses against bark beetles and their fungal associates. Front Plant Sci 10:208

Harrington TC (2005) Ecology and evolution of mycophagous bark beetles and their fungal partners. In: Vega FE, Blackwell M (eds) Ecological and evolutionary advances in insect-fungal associations. Oxford University Press, Oxford, England, pp 257-291

Harrington TC, Yun HY, Lu S-S, Goto H, Aghayeva DN, Fraedrich SW (2011) Isolations from the redbay ambrosia beetle, Xyleborus glabratus, confirm that the laurel wilt pathogen, Raffaelea lauricola, originated in Asia. Mycologia 103(5):1028-1036

Heidorn PB (2008) Shedding light on the dark data in the long tail of science. Libr Trends 57:280-299

Hijii N, Kajimura H, Urano T, Kinuura H, Itami H (1991) The mass mortality of oak trees induced by Platypus quercivorus Murayama and Platypus calamus Blandford (Coleoptera: Platypodidae). Journal of the Japanese Forestry Society 73:471-476

Hlásny T, Turčáni M (2013) Persisting bark beetle outbreak indicates the unsustainability of secondary Norway spruce forests: case study from Central Europe. Ann For Sci 70:481-491

Hofstetter RW, Dinkins-Bookwalter J, Davis TS, Klepzig KD (2015) Symbiotic associations of bark beetles. In: Vega FE, Hofstetter RW (eds) Bark Beetles. Academic Press, San Diego, pp 209-245
Huang Y-T, Skelton J, Hulcr J (2019) Multiple evolutionary origins lead to diversity in the metabolic profiles of ambrosia fungi. Fungal Ecol 38:80-88

Huang Y-T, Skelton J, Hulcr J (2020) Lipids and small metabolites provisioned by ambrosia fungi to symbiotic beetles are phylogeny-dependent, not convergent. ISME J 14(5):1089-1099

Hughes MA, Riggins JJ, Koch FH, Cognato AI, Anderson C, Formby JP, Dreaden TJ, Ploetz RC, Smith JA (2017) No rest for the laurels: symbiotic invaders cause unprecedented damage to southern USA forests. Biol Invasions 19:2143-2157

Hulcr J, Stelinski LL (2017) The ambrosia symbiosis: from evolutionary ecology to practical management. Ann Rev Entomology 62:285303

Hulcr J, Rountree NR, Diamond SE, Stelinski LL, Fierer N, Dunn RR (2012) Mycangia of ambrosia beetles host communities of bacteria. Microb Ecol 64:784-793

iDigBio 2018. www.idigbio.org/portal

Johnson AJ, McKenna DD, Jordal BH, Cognato AI, Smith SM, Lemmon AR, Lemmon EM, Hulcr J (2018) Phylogenomics clarifies repeated evolutionary origins of inbreeding and fungus farming in bark beetles (Curculionidae, Scolytinae). Mol Phylogenet Evol 1(127):229238

Jusino MA, Skelton J, Chen CC, Hulcr J, Smith ME (2020) Sexual reproduction and saprotrophic dominance by the ambrosial fungus Flavodon subulatus (= Flavodon ambrosius). Accepted. Fungal Ecology, in press

Karnosky DF (1979) Dutch elm disease: a review of the history, environmental implications, control, and research needs. Environ Conserv 6:311-322

Kasson MT, Wickert KL, Stauder CM, Macias AM, Berger MC, Simmons DR, Short DPG, DeVallance DB, Hulcr J (2016) Mutualism with aggressive wood-degrading Flavodon ambrosius (Polyporales) facilitates niche expansion and communal social structure in Ambrosiophilus ambrosia beetles. Fungal Ecol 23:86-96

Kendra PE, Montgomery WS, Niogret J, Epsky ND (2013) An uncertain future for American Lauraceae: a lethal threat from redbay ambrosia beetle and laurel wilt disease (a review). Am J Plant Sci 4:727-738

Kolarík M, Kubátová A, Hulcr J, Pazoutová S (2008) Geosmithia fungi are highly diverse and consistent bark beetle associates: evidence from their community structure in temperate Europe. Microb Ecol 55:65-80

Kolb T, Keefover-Ring K, Burr SJ, Hofstetter R, Gaylord M, Raffa KF (2019) Drought-mediated changes in tree physiological processes weaken tree defenses to bark beetle attack. J Chem Ecol 45:888-900

Kostovcik M, Bateman CC, Kolarik M, Stelinski LL, Jordal BH, Hulcr J (2015) The ambrosia symbiosis is specific in some species and promiscuous in others: evidence from community pyrosequencing. ISME J 9:126-138

Kovach J, Gorsuch CS (1985) Survey of ambrosia beetle species infesting South Carolina 353 peach orchards and a taxonomic key for the most common species. Journal of agricultural entomology 2(3) 354:238-247

Kühnholz S, Borden JH, Uzunovic A (2001) Secondary ambrosia beetles in apparently healthy trees: adaptations, potential causes and suggested research. Integr Pest Manag Rev 6:209-219

Lehenberger M, Biedermann PHW, Benz JP (2019) Molecular identification and enzymatic profiling of Trypodendron (Curculionidae: Xyloterini) ambrosia beetle-associated fungi of the genus Phialophoropsis (Microascales: Ceratocystidaceae). Fungal Ecol 38:89-97

Li Y, Simmons DR, Bateman CC, Short DPG, Kasson MT, Rabaglia RJ, Hulcr J (2015) New fungus-insect symbiosis: Culturing, molecular, and histological methods determine saprophytic Polyporales mutualists of Ambrosiodmus ambrosia beetles. PloS One 10:e137689

Li Y, Huang Y-T, Kasson MT, Macias AM, Skelton J, Carlson PS, Yin M, Hulcr J (2018) Specific and promiscuous ophiostomatalean fungi 
associated with Platypodinae ambrosia beetles in the southeastern United States. Fungal Ecol 35:42-50

Lindahl BD, Henrik Nilsson R, Tedersoo L, Abarenkov K, Carlsen T, Kjøller R, Kõljalg U, Pennanen T, Rosendahl S, Stenlid J, Kauserud H (2013) Fungal community analysis by high-throughput sequencing of amplified markers - a user's guide. New Phytol 199:288-299

Madin J, Bowers JS, Schildhauer M, Jones MB (2008) Advancing ecological research with ontologies. Trends Ecol Evol 23(3):159-168

Mageroy MH, Christiansen E, Långström B, Borg-Karlson A, Solheim H, Björklund N, Zhao T, Schmidt A, Fossdal CG, Krokene P (2019) Priming of inducible defenses protects Norway spruce against treekilling bark beetles. Plant Cell Environ 2019:1-11

Mayers CG, Bateman CC, Harrington TC (2018) New Meredithiella species from mycangia of Corthylus ambrosia beetles suggest genus-level coadaptation but not species-level coevolution. Mycologia 110:63-78

Mayers CG, Harrington TC, Masuya H, Jordal BH, McNew DL, Shih HH, Roets F, Kietzka GJ (2019) Patterns of coevolution between ambrosia beetle mycangia and the Ceratocystidaceae, with five new fungal genera and seven new species. Persoonia-Molecular Phylogeny and Evolution of Fungi 44:41-66

Michener W, Vieglais D, Vision T, Kunze J, Cruse P, Janée G (2011) DataONE: data observation network for earth - preserving data and enabling innovation in the biological and environmental sciences. D-Lib Magazine 17:1-2

Miller KE, Inward DJG, Gomez-Rodriguez C, Baselga A, Vogler AP (2019) Predicting the unpredictable: how host specific is the mycobiota of bark and ambrosia beetles? Fungal Ecol 42:100854 1000866

Moore BD, Andrew RL, Külheim C, Foley WJ (2014) Explaining intraspecific diversity in plant secondary metabolites in an ecological context. New Phytol 201:733-750

Mueller UG, Gerardo NM, Aanen DK, Six DL, Schultz TR (2005) The evolution of agriculture in insects. Annu Rev Ecol Evol Syst 36: 563-595

Mueller UG, Kardish MR, Ishak HD, Wright AM, Solomon SE, Bruschi SM, Carlson AL, Bacci M Jr (2018) Phylogenetic patterns of antfungus associations indicate that farming strategies, not only a superior fungal cultivar, explain the ecological success of leafcutter ants. Mol Ecol 27:2414-2434

Nilsson RH, Henrik Nilsson R, Ryberg M, Kristiansson E, Abarenkov K, Larsson K-H, Kõljalg U (2006) Taxonomic reliability of DNA sequences in public sequence databases: a fungal perspective. PloS One 1:e59

Nilsson RH, Henrik Nilsson R, Anslan S, Bahram M, Wurzbacher C, Baldrian P, Tedersoo L (2019) Mycobiome diversity: highthroughput sequencing and identification of fungi. Nat Rev Microbiol 17:95-109

Nobre T, Rouland-Lefèvre C, Aanen DK (2010) Comparative biology of fungus cultivation in termites and ants. In: Biology of termites: a modern synthesis 2010. Springer, Dordrecht, pp 193-210

O’Donnell K, Sink S, Libeskind-Hadas R, Hulcr J, Kasson MT, Ploetz RC, Konkol JL, Ploetz JN, Carrillo D, Campbell A, Duncan RE (2015) Discordant phylogenies suggest repeated host shifts in the Fusarium-Euwallacea ambrosia beetle mutualism. Fungal Genet Biol 82:277-290

Palmer JM, Jusino MA, Banik MT, Lindner DL (2018) Non-biological synthetic spike-in controls and the AMPtk software pipeline improve mycobiome data. PeerJ 6:e4925

Parr CS, Cummings MP (2005) Data sharing in ecology and evolution. Trends Ecol Evol 20(7):362-363
Pec GJ, Karst J, Sywenky AN, Cigan PW, Erbilgin N, Simard SW, Cahill JF (2015) Rapid increases in forest understory diversity and productivity following a mountain pine beetle (Dendroctonus ponderosae) outbreak in pine forests. PLoS One 10:e124691

Platt JR (1964) Strong inference: certain systematic methods of scientific thinking may produce much more rapid progress than others. Science 146:347-353

Postma J, Goossen-van de Geijn H (2016) Twenty-four years of Dutch trig® application to control Dutch elm disease. Biocontrol 61:305-312

Raffa KF (2014) Terpenes tell different tales at different scales: glimpses into the chemical ecology of conifer - bark beetle - microbial interactions. J Chem Ecol 40:1-20

Raffa KF, Bonello P, Orrock JL (2020) Why do entomologists and plant pathologists approach trophic relationships so differently? Identifying biological distinctions to foster synthesis. New Phytol 225:609-620

Rassati D, Marini L, Malacrinò A (2019) Acquisition of fungi from the environment modifies ambrosia beetle mycobiome during invasion. PeerJ 7:e8103

Reichman OJ, Jones MB, Schildhauer MP (2011) Challenges and opportunities of open data in ecology. Science 331(6018):703-705

Roberts H (1977) When ambrosia beetles attack mahogany trees in Fiji. Unasylva 29:25-28

Saucedo JR, Ploetz RC, Konkol JL, Ángel M, Mantilla J, Menocal O, Carrillo D (2018). Nutritional symbionts of a putative vector, Xyleborus bispinatus, of the laurel wilt pathogen of avocado, Raffaelea lauricola . Symbiosis 75, 29-38

Six DL (2003) Bark beetle-fungus symbioses. In: Bourtzis K, Miller T (eds) Insect symbiosis. CRC Press, New York, pp 97-114

Six DL (2020) A major symbiont shift supports a major niche shift in a clade of tree-killing bark beetles. Ecol Entomol 45(2):190-201

Six DL, Elser JJ (2019) Extreme ecological stoichiometry of a bark beetle-fungus mutualism. Ecol Entomol 44:543-551

Skelton J, Johnson AJ, Jusino MA, Bateman CC, Li Y, Hulcr J (2019a) A selective fungal transport organ (mycangium) maintains coarse phylogenetic congruence between fungus-farming ambrosia beetles and their symbionts. Proc R Soc B 286:20182127

Skelton J, Jusino MA, Carlson PS, Smith K, Banik MT, Lindner DL, Palmer JM, Hulcr J (2019b) Relationships among wood-boring beetles, fungi, and the decomposition of forest biomass. Mol Ecol 28:4971-4986

Smith SM, Beaver RA, Cognato AI, Hulcr J, Redford AJ (2019a) Southeast Asian Ambrosia beetle ID. USDA APHIS Identification Technology Program (ITP) and Michigan State University. Fort Collins, $\mathrm{CO}$

Smith SM, Gomez DF, Beaver RA, Hulcr J, Cognato AI (2019b) Reassessment of the species in the Euwallacea fornicatus (Coleoptera: Curculionidae: Scolytinae) complex after the rediscovery of the "lost" type specimen. Insects 10:261-272

Tarno H, Septia ED, Aini LQ (2016) Microbial community associated with ambrosia beetle, Euplatypus parallelus on sonokembang, Pterocarpus indicus in Malang. Agrivita Journal of Agricultural Science 38:312-320

Thatcher RC (1981) In: Thatcher RC, Searcy JL, Coster JE, Hertel GD (eds) The Southern Pine Beetle. U.S. Department of Agriculture

Turbelin AJ, Malamud BD, Francis RA (2017) Mapping the global state of invasive alien species: patterns of invasion and policy responses. Global Ecology and Biogeography: A Journal of Macroecology 26:78-92

Vanderpool D, Bracewell RR, McCutcheon JP (2018) Know your farmer: ancient origins and multiple independent domestications of ambrosia beetle fungal cultivars. Mol Ecol 27(8):2077-2094 
Vega FE, Biedermann PH (2019) On interactions, associations, mycetangia, mutualists and symbiotes in insect-fungus symbioses 2019 Dec 24:100909. Fungal Ecol 44:100909

Veselská T, Skelton J, Kostovčík M, Hulcr J, Baldrian P, Chudíčková M, Cajthaml T, Vojtová T, Garcia-Fraile P, Kolařík M (2019) Adaptive traits of bark and ambrosia beetle-associated fungi. Fungal Ecol 41: $165-176$

Wallace A (1859) Note on the habits of Scolytidae and Bostrichidae. Transactions of the American Entomological Society London 5: $218-220$
Wood SL (2007) Bark and Ambrosia beetles of South America (Coleoptera, Scolytidae). Monte L. Bean Life Science Museum, Brigham Young University, Provo, Utah

Publisher's note Springer Nature remains neutral with regard to jurisdictional claims in published maps and institutional affiliations. 